\title{
Targeted antenatal anti-D prophylaxis for RhD-negative pregnant women: a systematic review
}

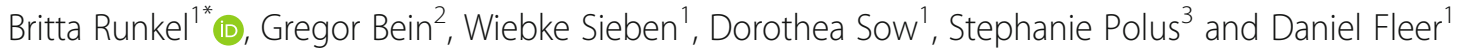

\begin{abstract}
Background: All non-sensitized Rhesus D (RhD)-negative pregnant women in Germany receive antenatal anti-D prophylaxis without knowledge of fetal RhD status. Non-invasive prenatal testing (NIPT) of cell-free fetal DNA in maternal plasma could avoid unnecessary anti-D administration. In this paper, we systematically reviewed the evidence on the benefit of NIPT for fetal RhD status in RhD-negative pregnant women.
\end{abstract}

Methods: We systematically searched several bibliographic databases, trial registries, and other sources (up to October 2019) for controlled intervention studies investigating NIPT for fetal RhD versus conventional anti-D prophylaxis. The focus was on the impact on fetal and maternal morbidity. We primarily considered direct evidence (from randomized controlled trials) or if unavailable, linked evidence (from diagnostic accuracy studies and from controlled intervention studies investigating the administration or withholding of anti-D prophylaxis). The results of diagnostic accuracy studies were pooled in bivariate meta-analyses.

Results: Neither direct evidence nor sufficient data for linked evidence were identified. Meta-analysis of data from about 60,000 participants showed high sensitivity (99.9\%; 95\% Cl [99.5\%; 100\%] and specificity (99.2\%; 95\% Cl [98.5\%; 99.5\%]).

Conclusions: NIPT for fetal RhD status is equivalent to conventional serologic testing using the newborn's blood. Studies investigating patient-relevant outcomes are still lacking.

Keywords: Genotyping techniques, Rh-Hr blood-group system, Fetus, Benefit assessment, Systematic review

\section{Bulleted statements}

- what's already known about this topic? Non-invasive prenatal testing (NIPT) for fetal RhD from maternal plasma may enable targeted anti-D prophylaxis for RhD-negative women carrying an RhD-positive fetus.

- what does this study add? NIPT of fetal RhD shows high sensitivity and specificity and is equivalent to conventional postnatal testing using a blood sample of the newborn.
* Correspondence: britta.runkel@iqwig.de

${ }^{1}$ Institute for Quality and Efficiency in Health Care (IQWiG), Cologne,

Germany

Full list of author information is available at the end of the article

\section{Background}

During pregnancy, a Rhesus D ( $\mathrm{RhD}$ )-negative woman may develop antibodies if her fetus is RhD-positive. These maternal allo-antibodies directed against fetal red cell surface antigens that the mother herself lacks can lead to hemolytic disease of the fetus and newborn (HDFN) [1]. Anti-D immunoglobulin (anti-D) administration was introduced in the early 1970 s to reduce the incidence of alloimmunization (sensitization) of pregnant women to the $\mathrm{D}$ antigen and subsequently the incidence of HDFN, which has since decreased dramatically [2]. In many countries, the current policy is to administer anti-D to non-sensitized RhD-negative pregnant women in the 28th week of gestation [3]. After birth, the cord blood is phenotyped and postnatal anti-D prophylaxis is offered only if the newborn is $\mathrm{RhD}$-positive.

(c) The Author(s). 2020 Open Access This article is distributed under the terms of the Creative Commons Attribution 4.0 International License (http://creativecommons.org/licenses/by/4.0/), which permits unrestricted use, distribution, and reproduction in any medium, provided you give appropriate credit to the original author(s) and the source, provide a link to the Creative Commons license, and indicate if changes were made. The Creative Commons Public Domain Dedication waiver (http://creativecommons.org/publicdomain/zero/1.0/) applies to the data made available in this article, unless otherwise stated. 
In a Cochrane review of 6 randomized controlled trials (RCTs), postnatal anti-D prophylaxis was shown to be effective in reducing the incidence of sensitization 6 months after birth and in a subsequent pregnancy [2]; the benefits were seen when anti-D was given within $72 \mathrm{~h}$ of birth, with higher doses being more effective than lower ones. However, postnatal prophylaxis does not prevent antenatal sensitization [4]. The current policy of universal antenatal anti-D administration leads to approximately 50,000 RhDnegative pregnant women per year in Germany receiving anti-D prophylaxis even though they are carrying an $\mathrm{RhD}-$ negative fetus [5].

Non-invasive prenatal testing (NIPT) for fetal RhD from maternal plasma may enable anti-D prophylaxis to be withheld from $\mathrm{RhD}$-negative women carrying an $\mathrm{RhD}$-negative fetus. As early as 1998, Lo et al. [6] described the presence of fetal DNA in maternal plasma and the possibility of non-invasive determination of the fetal $\mathrm{RhD}$ status. These findings enable non-invasive, risk-free antenatal testing, which is mostly performed using the real-time polymerase chain reaction (PCR).

The aim of the current article was to systematically review the evidence on the benefit of NIPT for fetal RhD status in RhD-negative pregnant women and subsequent targeted anti-D prophylaxis. The focus of the assessment was on patient-relevant outcomes.

\section{Methods}

\section{Protocol and methodological approach}

IQWiG's responsibilities and general methods are described in its methods paper [7]. The methods for the present assessment were defined a priori and published in a German-language protocol on the website of the German Institute for Quality and Efficiency in Health Care (IQWiG) [8]. The full German-language report including the original literature search [9], as well as an English-language extract [10], are also available on the website. The report is currently being used to inform a reimbursement decision on future $\mathrm{RhD}$ testing in Germany, thus potentially affecting about 750.000 pregnant women per year.

An update search was conducted for the current article, which was written according to the PRISMA statement [11] (see Additional file 1).

\section{Eligibility criteria}

The target population comprised non-sensitized RhDnegative pregnant women investigated in controlled intervention studies of the diagnostic-therapeutic chain. The test intervention was NIPT for fetal $\mathrm{RhD}$, with subsequent administration or withholding of anti-D prophylaxis, depending on the test result. The control intervention was conventional anti-D prophylaxis for all non-sensitized $\mathrm{RhD}$-negative pregnant women using the anti-D dose approved in Germany. The patient-relevant outcomes investigated included rates of mortality, HDFN and adverse events as well as health-related quality of life (if meaningful, referring to both maternal and fetal or pediatric outcomes). Sensitization rates were investigated as a surrogate outcome for HDFN.

If the kind of direct evidence described above was not available, we planned to apply a linked evidence approach [12].

We considered the following evidence and study types: Either direct evidence from RCTs of the diagnostictherapeutic chain (if not available, prospective intervention studies were also considered). Or, if no direct evidence was available, linked evidence [12] from studies on diagnostic accuracy, together with controlled intervention studies investigating the benefit (prevention of sensitization) and harm (adverse events) of antenatal anti-D prophylaxis. The detailed eligibility criteria are presented in Table 1.

\section{Search strategy and study selection}

We searched for relevant primary studies and secondary publications (systematic reviews and HTA reports) in MEDLINE (1946 to October 2019) and EMBASE (1974 to October 2019) via Ovid as well as in the Cochrane Central Register of Controlled Trials (October 2019). The Cochrane Database of Systematic Reviews (Cochrane Reviews), the Database of Abstracts of Reviews of Effects (Other Reviews), and the Health Technology Assessment Database (Technology Assessments) were searched for relevant secondary publications. In addition, we screened web-based trial registries (ClinicalTrials.gov, International Clinical Trials Registry Platform Search Portal, and the EU Clinical Trials Register). The search strategy, which was developed by one information specialist and checked by another, is presented in Additional file 2. We also screened the websites of the European Medicines Agency and the US Food and Drug Administration.

Two reviewers independently screened titles and abstracts of the citations retrieved to identify potentially eligible primary and secondary publications. The full texts of these articles were obtained and independently evaluated by the same two reviewers applying the full set of inclusion and exclusion criteria. Disagreements were resolved by consensus. Study selection was performed in IQWiG's internal web-based trial selection database (webTSDB) [13]. Endnote X9 was used for citation management.

\section{Data extraction}

The individual steps of the data extraction and risk-of-bias assessment procedures were always conducted by one person and checked by another; disagreements were resolved by consensus. Details of the studies were extracted using standardized tables developed and routinely used by 
Table 1 Eligibility criteria

\begin{tabular}{|c|c|c|c|c|}
\hline & \multirow{2}{*}{$\begin{array}{l}\text { Direct evidence } \\
\text { intervention studies }\end{array}$} & \multicolumn{3}{|l|}{ Linked evidence } \\
\hline & & diagnostic accuracy study & \multicolumn{2}{|l|}{ intervention studies } \\
\hline Population & $\begin{array}{l}\text { - RhD-negative pregnant women without } \\
\text { sensitization }\end{array}$ & $\begin{array}{l}\text { - RhD-negative pregnant } \\
\text { women without sensitization }\end{array}$ & \multicolumn{2}{|c|}{$\begin{array}{l}\text { - RhD-negative pregnant } \\
\text { women without sensitization }\end{array}$} \\
\hline Study intervention & $\begin{array}{l}\text { - non-invasive prenatal RhD-testing of the } \\
\text { fetus and omission of antenatal anti-D } \\
\text { prophylaxis in the case of an RhD- } \\
\text { negative fetus }\end{array}$ & $\begin{array}{l}\text { - non-invasive prenatal } \\
\text { RhD-testing of the fetus }\end{array}$ & \multicolumn{2}{|c|}{$\begin{array}{l}\text { - administration of anti-D } \\
\text { prophylaxis }\end{array}$} \\
\hline \multirow[t]{2}{*}{ Control intervention } & \multirow[t]{2}{*}{$\begin{array}{l}\text { - anti-D prophylaxis for all } \\
\text { RhD-negative pregnant women }\end{array}$} & \multirow[t]{2}{*}{$\begin{array}{l}\text { - postnatal RhD-testing of } \\
\text { the newborn }\end{array}$} & \multicolumn{2}{|c|}{$\begin{array}{l}\text { - no antenatal administration } \\
\text { of anti-D prophylaxis }\end{array}$} \\
\hline & & & Benefits & Harms \\
\hline \multirow{4}{*}{$\begin{array}{l}\text { Patient-relevant outcomes/ } \\
\text { diagnostic accuracy measures }\end{array}$} & - mortality & \multirow{4}{*}{$\begin{array}{l}\text { - test accuracy (sensitivity, } \\
\text { specificity, false-negative } \\
\text { rate, false-positive rate) }\end{array}$} & • mortality & • mortality \\
\hline & $\begin{array}{l}\text { • HDFN (surrogate outcome: } \\
\text { sensitization) }\end{array}$ & & \multirow{2}{*}{$\begin{array}{l}\text { - HDFN (surrogate } \\
\text { outcome: } \\
\text { sensitization) }\end{array}$} & - adverse events \\
\hline & - adverse events & & & \multirow{2}{*}{$\begin{array}{c}\text { - health-related } \\
\text { quality of life }\end{array}$} \\
\hline & - health-related quality of life & & $\begin{array}{l}\text { - health-related } \\
\text { quality of life }\end{array}$ & \\
\hline \multirow[t]{3}{*}{ Study type } & • RCTs & \multirow[t]{3}{*}{ - prospective cohort studies } & • RCTs & • RCTs \\
\hline & $\begin{array}{l}\text { - prospective, non-randomized } \\
\text { controlled intervention studies }\end{array}$ & & \multirow[t]{2}{*}{$\begin{array}{l}\text { - prospective, non- } \\
\text { randomized con- } \\
\text { trolled interven- } \\
\text { tion studies }\end{array}$} & $\begin{array}{l}\text { - prospective, } \\
\text { non-randomized } \\
\text { controlled } \\
\text { intervention studies }\end{array}$ \\
\hline & & & & $\begin{array}{l}\text { - cohort studies (also } \\
\text { retrospective or } \\
\text { with historical } \\
\text { controls) }\end{array}$ \\
\hline
\end{tabular}

HDFN: hemolytic disease of the fetus and newborn

IQWiG. Depending on the study question (comparison of interventions or evaluation of diagnostic accuracy) we extracted information on study design, sample size, patientrelevant outcomes or diagnostic accuracy, location and period during which the study was conducted, dropout rate, gestational age, treatment regimen and control treatment or index test and reference standard, as well as risk-of-bias items (see below).

\section{Assessment of risk of bias}

We assessed the risk of bias for individual studies, as well as for each outcome, and rated these risks as "high" or "low".

For controlled intervention studies, the risk of bias was assessed by determining the adequacy of the following quality criteria, which closely follow the criteria of the Cochrane risk-of-bias tool [14]): generation of random allocation sequence or whether both treatment groups were studied in parallel, allocation concealment or comparability of groups, blinding of participants and investigators, as well as selective outcome reporting. If the risk of bias on the study level was rated as "high", the risk of bias on the outcome level was also generally rated as "high". The risk of bias for each outcome was assessed by determining the adequacy of the following quality criteria: blinding of outcome assessors, application of the intention-to-treat (ITT) principle, and selective outcome reporting.
For studies on diagnostic accuracy, the risk of bias was assessed by determining the adequacy of the following quality criteria following QUADAS-2 [15]: patient selection, index test, reference standard, as well as flow and timing. Concerns about applicability were assessed by determining the adequacy of the following quality criteria: patient selection, index test and reference standard.

The risk of bias determines the confidence in the conclusions drawn from the study data and can be used to explore possible reasons for heterogeneity if the studies differ in their risk of bias.

\section{Data analysis}

For the statistical analysis of controlled intervention studies, we used the results from the ITT analysis. We reported the treatment effects as odds ratios (ORs), including 95\% confidence intervals (CIs), for binary outcomes. We conducted a random effects meta-analysis of intervention studies using the Knapp-Hartung method [16] as well as sensitivity analyses using the Mantel-Haenszel method and a Betabinomial model. No subgroup analyses were conducted.

Separate meta-analyses were performed to pool the results of diagnostic accuracy studies. Sensitivities and specificities were summarized in a bivariate meta-analysis. Model parameters were estimated by means of a generalized linear mixed model. No sensitivity or subgroup analyses were conducted. 
All calculations were performed with the statistical software SAS.

\section{Results}

Literature search (see Figs. 1 and 2 for flowchart)

Overall, 2237 studies were screened. No studies of the diagnostic-therapeutic chain were identified. 70 studies on diagnostic accuracy including approximately 66,000 participants were identified (all in bibliographic databases), of which the 12 largest (including over $90 \%$ of the total study population) were included in the analysis [5, 17-28]. Two controlled intervention studies investigating the benefit (prevention of sensitization) of antenatal anti-D prophylaxis were identified (in bibliographic databases). However, they used a low and non-approved dose for anti-D prophylaxis $[29,30]$. The results of these off-label studies are described below. No studies investigating harm (adverse events) from anti-D prophylaxis were identified.

\section{Study characteristics}

Table 2 presents the main characteristics of the 12 largest diagnostic accuracy studies and the two off-label studies on anti-D prophylaxis.

\section{Risk of bias}

Both off-label studies on anti-D prophylaxis showed a high risk of bias on the study and outcome level, for example, because of unclear information on the blinding of patients and investigators and/or an inappropriate ITT analysis. In 11 of the 12 diagnostic accuracy studies, the risk of bias was high in the total score (Table 3). However, the pooled estimate of all studies were similar to the results of the study with the low risk of bias.

\section{Effects of antenatal anti-D prophylaxis}

The meta-analysis of the results of the two off-label studies (Additional file 3) showed no significant differences in sensitization at the time of delivery (OR 0.33, $95 \%$ CI $[0 ; 123,851]$, number of participants $=2297$, number of studies $=2, \mathrm{I}^{2}=51 \%$ ). The $\mathrm{CI}$ is very wide

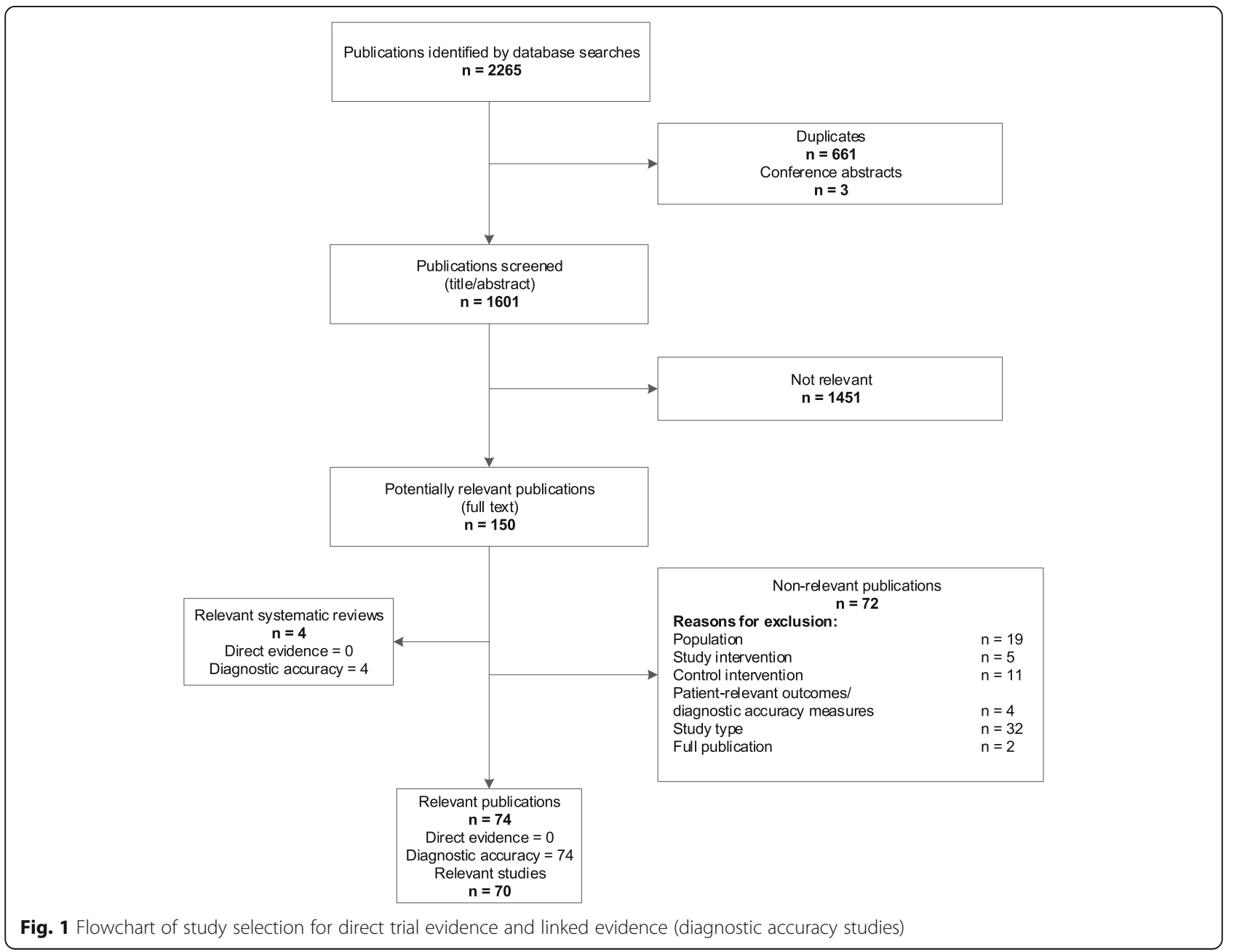




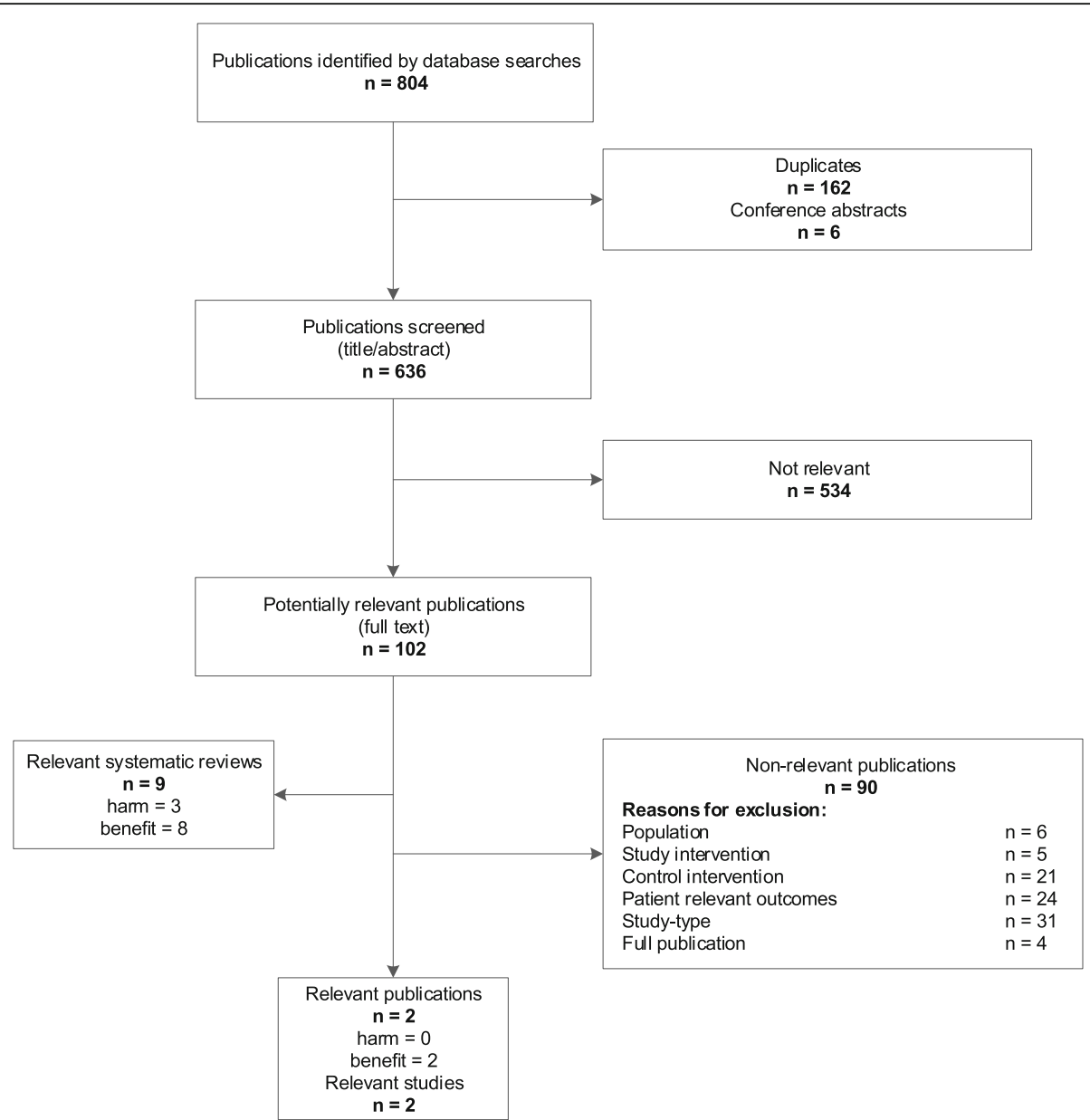

Fig. 2 Flowchart of study selection for linked evidence (controlled intervention studies - benefit and harm of anti-D prophylaxis)

and the effect could not be estimated with adequate precision. We therefore conducted different sensitivity analyses with 2 different meta-analysis methods, the Mantel-Haenszel (MH) method and the beta-binomial model (BBM). Both led to more precise estimates $(\mathrm{MH}$ : 0.37 [0.13; 1.06], number of participants $=2297$, number of studies $=2, \mathrm{I}^{2}=51 \%$; BBM $0.30[0.07 ; 1.26]$, number of participants $=2297$, number of studies $=2$ ), but neither showed a significant difference between the test and control groups.

\section{Diagnostic accuracy}

Sensitivities and specificities from the 12 studies are described comparatively in Table 4 . The bivariate metaanalysis showed high values for both measures of diagnostic accuracy of NIPT in RhD-negative pregnant women (sensitivity: 99.9\% (95\% CI [99.5\%; 100\%]; specificity: $99.2 \%$ (95\% CI [98.5\%; 99.5\%], number of participants $=60,011$, number of studies $=12$ ). Two of the studies $[5,17]$ assessed discordant results of ante- and postnatal tests by genetic testing. They found that the postnatal test also produced a few incorrect test results (about 35 false-negative results out of 27,000 tests due to $\mathrm{RhD}$ variants or confusion of the samples), indicating that both tests can be regarded as equivalent.

\section{Discussion}

The current review shows a lack of studies investigating patient-relevant outcomes after NIPT for fetal RhD status in RhD-negative pregnant women and subsequent targeted anti-D prophylaxis. The analysis of diagnostic accuracy studies shows that NIPT has a high sensitivity and specificity.

\section{Comparison with the literature Anti-D prophylaxis}

The Cochrane review by McBain 2015 [4] included the same two off-label studies on antenatal anti-D prophylaxis described in our review $[29,30]$. In accordance with our findings, the authors stated that these two studies do not provide conclusive evidence that the use of anti-D 


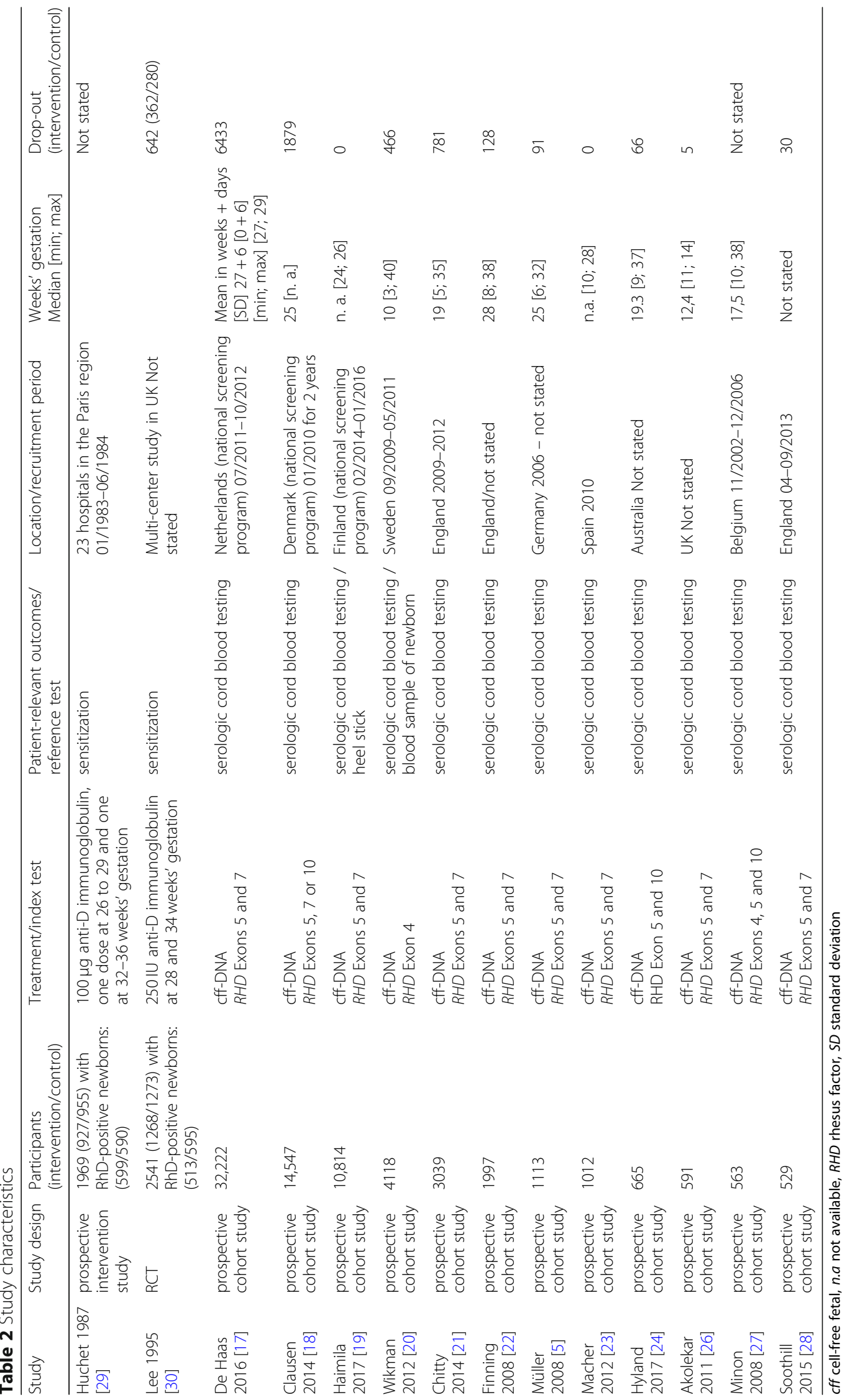


Table 3 Risk of bias of included studies (QUADAS 2) and concerns regarding applicability

\begin{tabular}{|c|c|c|c|c|c|}
\hline Study & Patient selection & Index test & Reference standard & Flow and timing & Applicability concerns - total \\
\hline De Haas 2016 & low & unclear & low & high & low \\
\hline Clausen 2014 & low & unclear & unclear & high & low \\
\hline Haimila 2017 & low & unclear & unclear & low & low \\
\hline Wikman 2012 & low & unclear & unclear & high & low \\
\hline Chitty 2014 & unclear & low & unclear & high & low \\
\hline Finning 2008 & unclear & unclear & low & low & low \\
\hline Müller 2008 & low & unclear & unclear & low & low \\
\hline Macher 2012 & low & unclear & unclear & low & low \\
\hline Hyland 2017 & low & unclear & unclear & low & low \\
\hline Akolekar 2011 & unclear & unclear & unclear & low & low \\
\hline Minon 2008 & low & unclear & unclear & low & low \\
\hline Soothill 2015 & low & low & low & low & low \\
\hline
\end{tabular}

during pregnancy shows a benefit in terms of incidence of Rhesus D sensitization.

A systematic review by Pilgrim 2009 [31] contained 12 studies (including one of the off-label studies [29] described in our review) with a high risk of bias, such as studies with historical controls, retrospective studies, and community intervention trials. They concluded that antenatal anti-D prophylaxis may reduce the incidence of sensitization. Furthermore, they noted that anti-D is associated with only minimal adverse effects.

In a systematic review by Turner 2012 [32], a pooled OR of 0.31 (95\% CI $[0.17 ; 0.56])$ was determined in an

Table 4 Diagnostic accuracy results

\begin{tabular}{|c|c|c|c|c|c|c|c|c|}
\hline Study & $\mathrm{n}$ & TP & FN & FP & TN & Inconclusive results (\%) ${ }^{\mathrm{a}, \mathrm{b}}$ & Sensitivity in \% $\left[95 \%\right.$ Cl] ${ }^{b}$ & Specificity in \% [95\% Cl] \\
\hline De Haas 2016 & 25,789 & 15,816 & 9 & 225 & 9739 & $0(0)^{c}$ & $99.9[99.9 ; 100]$ & $97.7[97.4 ; 98.0]$ \\
\hline Clausen 2014 & 12,668 & 7636 & 11 & 41 & 4706 & $274(2.2)$ & $99.9[99.7 ; 99.9]$ & $99.1[98.8 ; 99.4]$ \\
\hline Haimila 2017 & 10,814 & 7080 & 1 & 7 & 3640 & $86(0.80)$ & $100[99.9 ; 100]$ & $99.8[99.6 ; 99.9]$ \\
\hline Wikman 2012 & 3652 & 2236 & 55 & 15 & 1331 & $15^{\mathrm{b}}(0.4)$ & $97.6[96.9 ; 98.2]$ & $98.9[98.2 ; 99.4]$ \\
\hline \multirow[t]{2}{*}{ Chitty 2014} & $956^{d}$ & 535 & 1 & 4 & 341 & $75(7.8)$ & 99.8 [99.0; 100] & $98.8[97.1 ; 99.7]$ \\
\hline & $2288^{e}$ & 2563 & 19 & 18 & 1920 & $393(17.2)$ & $99.3[98.9 ; 99.6]$ & $99.1[98.5 ; 99.4]$ \\
\hline Finning 2008 & 1869 & 1118 & 3 & 14 & 670 & $64(3.4)$ & $99.7[99.2 ; 99.9]$ & $98.0[96.6 ; 98.9]$ \\
\hline Müller 2008 & 1022 & & & & & & & \\
\hline "Spin column"f & & $660^{b}$ & $2^{b}$ & $3^{b}$ & $357^{b}$ & $0(0)^{b}$ & $99.7[98.9 ; 100]$ & $99.2[97.6 ; 99.8]$ \\
\hline "Magnetic tips"f & & $661^{b}$ & $1^{b}$ & $7^{b}$ & $353^{b}$ & $0(0)^{b}$ & $99.8[99.2 ; 100]$ & 98.1 [96.0; 99.2] \\
\hline Macher 2012 & 1012 & 619 & 0 & 7 & 386 & $0(0)$ & $100[99.4 ; 100]$ & $98.2[96.4 ; 99.3]$ \\
\hline Hyland 2017 & 599 & 370 & 0 & 1 & 226 & $2(0.3)^{b}$ & 100 [99.0; 100] & $99.6[97.6 ; 100]$ \\
\hline Akolekar 2011 & 586 & 332 & 6 & 0 & 164 & $84(14.3)$ & $98.2[96.2 ; 99.3]$ & $100[97.8 ; 100]$ \\
\hline Minon 2008 & 545 & 360 & 0 & 0 & 185 & $0(0)$ & 100 [99.0; 100] & $100[98.0 ; 100]$ \\
\hline \multirow[t]{2}{*}{ Soothill 2015} & 499 & 267 & 0 & 1 & 170 & $61^{9}(12.2)$ & 100 [98.6; 100] & $99.4[96.8 ; 100]$ \\
\hline & & & & & & pooled estimate $^{h}$ & $99.9[99.5 ; 100]$ & $99.2[98.5 ; 99.5]$ \\
\hline
\end{tabular}

a: Proportion of study participants with inconclusive results

b: IQWiG's own calculation

c: $0.21 \%$ of samples were inconclusive (women with $\mathrm{RhD}$ variants). In this study these samples were categorized by the positive samples

$\mathrm{d}$ : Results of the largest cohort of this study (11 to 13 weeks' gestation). These results are included in the pooled effect

e: Summarized data for 2288 evaluated women with a total of 4913 data sets including up to 4 measurement points (multiple measurements). The number of blood samples is therefore shown here

f: "Spin column" and "magnetic tips" are two different methods for the extraction of cff-DNA from plasma samples. The patients with samples extracted by the spin column method are included in the pooled effect

g: Treated like positive samples

h: Generalized linear model to take into account the dependency between sensitivity and specificity

cff: cell-free fetal; FN: false negative; FP: false positive; Cl: confidence interval; n: number of evaluated participants; RHD: rhesus factor; TN: true negative; TP: true positive 
adjusted meta-analysis of 10 studies on the administration of antenatal anti-D prophylaxis and the incidence of sensitization. Among these were the two off-label studies described in our review and further studies with historical control groups. The authors concluded that there was strong evidence of the effectiveness of routine antenatal anti-D prophylaxis for prevention of sensitization.

\section{Diagnostic accuracy}

We identified 70 relevant studies on diagnostic accuracy, of which 58 included only a comparatively small number of participants (2 to 467). We therefore restricted our sample to the 12 largest studies, which comprised over $90 \%$ of the overall study population. A sufficiently accurate determination of the diagnostic accuracy of NIPT for fetal RhD was thus possible, showing high sensitivity and specificity.

Mackie 2017 [33] included 30 studies and found a sensitivity of $99.3 \%$ (95\% CI [98.2, 99.7\%]) and a specificity of $98.4 \%$ (95\% CI [96.4, 99.3\%]). These results are comparable to our findings, despite a differing study pool (only 2 of the 30 studies were included in our review).

A British National Institute for Health and Care Excellence (NICE) report from 2016 [34, 35] on diagnostic accuracy included eight studies exclusively using "high throughput" NIPT (six of these studies were included in our review). The corresponding HTA report [36] found that after 11 weeks of pregnancy only $1 \%$ of the samples showed an incorrect test result (almost all false-positive) and approximately $7 \%$ of the samples showed an inconclusive result. A pooled rate of false-negative results of $0.34 \%$ [95\% CI $[0.15 \% ; 0.76 \%)]$ was reported, which is comparable to the sensitivity determined in our review $(99.9 \%$ [95\% CI [99.5\%; 100\%]). According to NICE, if antenatal anti-D prophylaxis was administered only to RhDnegative pregnant women with $\mathrm{RhD}$-positive fetuses, this would result in potential cost savings between $£ 296,000$ and $£ 409,000$ per 100,000 pregnancies $[36,37]$. NICE has issued a positive recommendation for NIPT [38].

A French Haute Autorité de Santé (HAS) report on diagnostic accuracy from $2011[39,40]$ is based on 31 studies, which were not pooled in a meta-analysis. Despite the differing study pools (only two studies were included in our review), their results are comparable: the majority of the studies included (22 of 31 ) reported a sensitivity and specificity of over $95 \%$. HAS concluded that the expected benefit of NIPT was sufficient to justify reimbursement by the health insurance funds, and it is now being reimbursed in France. They recommend applying the test between the 11th and 28th week of pregnancy.

\section{Limitations}

The meta-analysis of diagnostic accuracy was limited by fact that the true fetal RhD status could not be determined by genetic testing in the primary studies. Only two studies resolved discrepancies between the ante- and postnatal test. As postnatal testing can also be incorrect, using postnatal test results as the reference standard might underestimate the true accuracy of the prenatal test. An additional limitation of the present review was the restriction of analyses to only the largest primary studies. However, the inclusion of all studies, regardless of sample size, would probably not have altered the main findings. Furthermore, the non-publication of negative findings is more common in smaller studies [41], so focusing on larger studies reduces bias.

\section{Ethical aspects}

With the implementation of NIPT for fetal RhD status, almost $40 \%$ of antenatal anti-D administrations could be saved per year in Germany [5]. Important aspects are not only the costs, but also ethical issues concerning the acquisition of anti-D: male donors are sensitized with a blood product to produce the vaccine and the number of donors worldwide is limited; most countries rely on imports.

\section{Conclusion}

In summary, NIPT for fetal RhD status shows high sensitivity and specificity and is equivalent to conventional postnatal testing using a blood sample of the newborn, which also produces a few incorrect test results. Some countries (e.g. Denmark and Netherlands) have already implemented NIPT and have abolished postnatal testing. However, as studies investigating the effects of NIPT on patient-relevant outcomes are still lacking, before its widespread implementation as the only test to determine RhD status, we recommend evaluating the benefit of NIPT in the respective health care settings.

\section{Supplementary information}

Supplementary information accompanies this paper at https://doi.org/10. 1186/s12884-020-2742-4

Additional file 1. PRISMA checklist

Additional file 2. Search strategy

Additional file 3: Table S5. Effects of antenatal anti-D prophylaxis

\footnotetext{
Abbreviations

BBM: beta-binomial model; Cl: Confidence interval; DNA: Deoxyribonucleic acid; HAS: Haute Autorité de Santé; HDFN: Hemolytic disease of the fetus and newborn; HTA: Health Technology Assessment; IQWiG: Institute for Quality and Efficiency in Health Care; ITT: Intention-to-treat; MH: MantelHaenszel; NICE: National Institute for Health and Care Excellence; NIPT: Noninvasive prenatal testing; OR: Odds ratio; PCR: Polymerase chain reaction; PRISMA: Preferred Reporting Items for Systematic Reviews and MetaAnalyses; QUADAS-2: Quality Assessment of Diagnostic Accuracy Studies 2; RCT: Randomized controlled trial; RhD: Rhesus D; webTSDB: Web-based trial selection database
} 


\section{Acknowledgements}

The authors thank Lisa Schell and Katrin Dreck for supporting study selection and data extraction, Inga Overesch for conducting the update search, Mandy Kromp for checking the data analysis, and Natalie McGauran for editorial support.

\section{Authors' contributions}

BR wrote the main part of the manuscript, made substantial contributions to the conception and design, and was involved in the acquisition and interpretation of the data. GB was involved in writing the manuscript and provided clinical expertise. WS performed all statistical analyses and was involved in the analysis and interpretation of the data. DS developed and conducted the literature search. SP was involved in the screening, collection and interpretation of data. DF made substantial contributions to the conception and design, was involved in the interpretation of the data and in writing the manuscript. All authors read and approved the final manuscript.

\section{Funding}

This research received non-financial support from the Institute for Quality and Efficiency in Health Care (IQWiG). Four of the six authors are IQWiG employees and were thus involved in the design of the study and collection, analysis, and interpretation of data and in writing the manuscript. This research received no specific grant from any funding agency in the public commercial or not-for-profit sectors.

\section{Availability of data and materials}

All data generated or analysed in this research are included in this published article or in the full German-language report, https://www.iqwig.de/download/D16-01_Bestimmung-fetaler-Rhesusfaktor_Abschlussbericht_v1-0.pd

\section{Ethics approval and consent to participate}

Not applicable.

\section{Consent for publication}

All authors read and approved the final version of the manuscript.

\section{Competing interests}

The authors declare no competing interests.

\section{Author details}

${ }^{1}$ Institute for Quality and Efficiency in Health Care (IQWiG), Cologne, Germany. ${ }^{2}$ Institute for Clinical Immunology and Transfusion Medicine, Justus-Liebig-University, Giessen, Germany. ${ }^{3}$ Institute for Research in Operative Medicine, Witten/Herdecke University, Cologne, Germany.

\section{Received: 9 May 2019 Accepted: 14 January 2020}

\section{Published online: 07 February 2020}

\section{References}

1. Urbaniak SJ, Greiss MA. RhD haemolytic disease of the fetus and newborn. Blood Rev. 2000;14:44-61.

2. Crowther CA, Middleton P. Anti-D administration after childbirth for preventing Rhesus alloimmunisation. Cochrane Database Syst Rev. 1997;(2): CD000021.

3. Sperling JD, Dahlke JD, Sutton D, Gonzales JM, Chauhan MD. Prevention of RhD alloimmunization: a comparison of four national guidelines. Am $\lrcorner$ Perinatol. 2018:35:110-9.

4. McBain RD, Crowther CA, Middleton P. Anti-D administration in pregnancy for preventing Rhesus alloimmunisation. Cochrane Database Syst Rev. 2015; (9):CD000020

5. Müller SP, Bartels I, Stein W, Emons G, Gutensohn K, Köhler M, et al. The determination of the fetal $\mathrm{D}$ status from maternal plasma for decision making on Rh prophylaxis is feasible. Transfusion (Paris). 2008:48:2292-301.

6. Lo YM, Hjelm NM, Fidler C, Sargent IL, Murphy MF, Chamberlain PF, et al. Prenatal diagnosis of fetal RhD status by molecular analysis of maternal plasma. N Engl J Med. 1998:339:1734-8.

7. Institute for Quality and Efficiency in Health Care. General methods: version 5.0. 2017. https://www.iqwig.de/download/General-Methods Version-5-0.pdf.

8. Institute for Quality and Efficiency in Health Care. Non-invasive determination of the fetal rhesus factor to prevent maternal rhesus sensitization: report plan [German]. 2017. https://www.iqwig.de/download/ D16-01_Bestimmung-fetaler-Rhesusfaktor_Berichtsplan_V1-0.pdf.

9. Institute for Quality and Efficiency in Health Care. Non-invasive determination of the fetal rhesus factor to prevent maternal rhesus sensitization: final report [German]. 2018. https://www.iqwig.de/download/D16-01_Bestimmung-fetalerRhesusfaktor_Abschlussbericht_V1-0.pdf. Accessed 21 Feb 2019.

10. Institute for Quality and Efficiency in Health Care. Non-invasive determination of the fetal rhesus factor to prevent maternal rhesus sensitization: extract. 2018. https://www.iqwig.de/download/D16-01 Determination-of-fetal-rhesus-factor_Extract-of-final-report_V1-0.pdf. Accessed 21 Feb 2019.

11. Hutton B, Salanti G, Caldwell DM, Chaimani A, Schmid CH, Cameron C, et al. The PRISMA extension statement for reporting of systematic reviews incorporating network meta-analyses of health care interventions: checklist and explanations. Ann Intern Med. 2015;162:777-84.

12. Merlin T, Lehman S, Hiller JE, Ryan P. The "linked evidence approach" to assess medical tests: a critical analysis. Int J Technol Assess Health Care. 2013;29:343-50

13. Hausner E, Ebrahim S, Herrmann-Frank A, Janzen $T$, Kerekes MF, Pischedda $M$, et al. Study selection by means of a web-based trial selection DataBase (webTSDB). Cochrane Database Syst Rev. 2011:16-7.

14. Higgins JP, Altman DG, Gotzsche PC, Juni P, Moher D, Oxman AD, et al. The Cochrane Collaboration's tool for assessing risk of bias in randomised trials. BMJ. 2011;343:d5928.

15. Whiting PF, Rutjes AW, Westwood ME, Mallett S, Deeks JJ, Reitsma JB, et al. QUADAS-2: a revised tool for the quality assessment of diagnostic accuracy studies. Ann Intern Med. 2011;155:529-36.

16. Hartung J. An alternative method for meta-analysis. Biom J. 1999;41:901-16.

17. De Haas M, Thurik FF, Van der Ploeg CP, Veldhuisen B, Hirschberg $H$, Soussan AA, et al. Sensitivity of fetal RHD screening for safe guidance of targeted anti-D immunoglobulin prophylaxis: prospective cohort study of a nationwide programme in the Netherlands. BMJ. 2016:355:15789.

18. Clausen FB, Steffensen R, Christiansen M, Rudby M, Jakobsen MA, Jakobsen $T R$, et al. Routine noninvasive prenatal screening for fetal RHD in plasma of RhD-negative pregnant women: 2 years of screening experience from Denmark. Prenat Diagn. 2014:34:1000-5.

19. Haimila K, Sulin K, Kuosmanen M, Sareneva I, Korhonen A, Natunen S, et al Targeted antenatal anti-D prophylaxis program for RhD-negative pregnant women: outcome of the first two years of a national program in Finland. Acta Obstet Gynecol Scand. 2017:96:1228-33.

20. Wikman AT, Tiblad E, Karlsson A, Olsson ML, Westgren M, Reilly M. Noninvasive single-exon fetal RHD determination in a routine screening program in early pregnancy. Obstet Gynecol. 2012;120:227-34.

21. Chitty LS, Finning K, Wade A, Soothill P, Martin B, Oxenford K, et al. Diagnostic accuracy of routine antenatal determination of fetal RHD status across gestation: population based cohort study. BMJ. 2014;349:95243.

22. Finning K, Martin P, Summers J, Massey E, Poole G, Daniels G. Effect of high throughput RHD typing of fetal DNA in maternal plasma on use of anti-RhD immunoglobulin in RhD negative pregnant women: prospective feasibility study. BMJ. 2008;336:816-8

23. Macher HC, Noguerol P, Medrano-Campillo P, Garrido-Marquez MR, RubioCalvo A, Carmona-Gonzalez M, et al. Standardization non-invasive fetal RHD and SRY determination into clinical routine using a new multiplex RT-PCR assay for fetal cell-free DNA in pregnant women plasma: results in clinical benefits and cost saving. Clin Chim Acta. 2012:413:490-4.

24. Hyland CA, Millard GM, O'Brien H, Schoeman EM. Non-invasive fetal RHD genotyping for RhD negative women stratified into RHD gene deletion or variant groups: comparative accuracy using two blood collection tube types. Pathology (Phila). 2017:49:757-64.

25. Hyland CA, Gardener GJ, Davies H, Ahvenainen M, Flower RL, Irwin D, et al. Evaluation of non-invasive prenatal RHD genotyping of the fetus. Med J Aust. 2009;191:21-5.

26. Akolekar R, Finning K, Kuppusamy R, Daniels G, Nicolaides KH. Fetal RHD genotyping in maternal plasma at 11-13 weeks of gestation. Fetal Diagn Ther. 2011;29:301-6.

27. Minon JM, Gerard C, Senterre JM, Schaaps JP, Foidart JM. Routine fetal RHD genotyping with maternal plasma: a four-year experience in Belgium. Transfusion (Paris), 2008:48:373-81.

28. Soothill PW, Finning K, Latham T, Wreford-Bush T, Ford J, Daniels G. Use of cffDNA to avoid administration of anti-D to pregnant women when the fetus is RhD-negative: implementation in the NHS. BJOG. 2015;122:1682-6. 
29. Huchet J, Dallemagne S, Huchet C, Brossard Y, Larsen M, Parnet-Mathieu F. Ante-partum administration of preventive treatment of Rh-D immunization in Rhesus-negative women: parallel evaluation of transplacental passage of fetal blood cells; results of a multicenter study carried out in the Paris region [French]. J Gynecol Obstet Biol Reprod (Paris). 1987;16:101-11.

30. Lee D, Rawlinson VI. Multicentre trial of antepartum low-dose anti-D immunoglobulin. Transfus Med. 1995;5:15-9.

31. Pilgrim $H$, Lloyd-Jones $M$, Rees $A$. Routine antenatal anti-D prophylaxis for RhD-negative women: a systematic review and economic evaluation. Health Technol Assess. 2009;13:iii, ix-xi, 1-103.

32. Turner RM, Lloyd-Jones M, Anumba DO, Smith GC, Spiegelhalter DJ, Squires $H$, et al. Routine antenatal anti-D prophylaxis in women who are $R h(D)$ negative: meta-analyses adjusted for differences in study design and quality. PLoS One. 2012;7:e30711

33. Mackie FL, Hemming K, Allen S, Morris RK, Kilby MD. The accuracy of cellfree fetal DNA-based non-invasive prenatal testing in singleton pregnancies: a systematic review and bivariate meta-analysis. BJOG. 2017;124:32-46.

34. National Institute for Health and Care Excellence. High-throughput noninvasive prenatal testing for fetal RHD genotype. 2016. https://www.nice. org.uk/guidance/dg25/resources/highthroughput-noninvasive-prenataltesting-for-fetal-rhd-genotype-1053691935685.

35. CRD/CHE Technology Assessment Group. High-throughput, non-invasive prenatal testing for fetal rhesus $\mathrm{D}$ status in RhD-negative women not known to be sensitised to the RhD antigen: a systematic review and economic evaluation. 2016. https://www.nice.org.uk/guidance/dg25/ documents/diagnostics-assessment-report.

36. Saramago P, Yang H, Llewellyn A, Walker R, Harden M, Palmer S, et al. Highthroughput non-invasive prenatal testing for fetal rhesus $\mathrm{D}$ status in RhDnegative women not known to be sensitised to the RhD antigen: a systematic review and economic evaluation. Health Technol Assess. 2018;22:1-172.

37. National Institute for Health and Care Excellence. New blood test for pregnant women could help thousands avoid unnecessary treatment. 2016. https://www.nice.org.uk/news/article/new-blood-test-for-pregnant-womencould-help-thousands-avoid-unnecessary-treatment.

38. National Institute for Health and Care Excellence. High-throughput noninvasive prenatal testing for fetal RHD genotype: recommendations. 2016. https://www.nice.org.uk/quidance/dg25/chapter/1-Recommendations.

39. Haute Autorité de Santé. Détermination prénatale du génotype RHD foetal à partir du sang maternel: rapport d'évaluation technologique. 2011. https:// www.has-sante.fr/portail/plugins/ModuleXitiKLEE/types/FileDocument/doXiti. jsp?id=c_1108581.

40. Haute Autorité de Santé. Détermination prénatale du génotype RHD foetal à partir du sang maternel: avis sur les actes. 2011. https://www.has-sante.fr/ portail/upload/docs/application/pdf/2011-10/avis_genotypage_foetal.pdf.

41. Guyatt GH, Oxman AD, Montori V, Vist G, Kunz R, Brozek J, et al. GRADE guidelines: 5. Rating the quality of evidence; publication bias. J Clin Epidemiol. 2011;64:1277-82.

\section{Publisher's Note}

Springer Nature remains neutral with regard to jurisdictional claims in published maps and institutional affiliations.

Ready to submit your research? Choose BMC and benefit from:

- fast, convenient online submission

- thorough peer review by experienced researchers in your field

- rapid publication on acceptance

- support for research data, including large and complex data types

- gold Open Access which fosters wider collaboration and increased citations

- maximum visibility for your research: over $100 \mathrm{M}$ website views per year

At $\mathrm{BMC}$, research is always in progress.

Learn more biomedcentral.com/submissions 